\title{
Public Health, Managed Care, and Pharmacy: An Evolving Trifecta
}

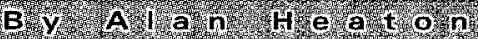

I $n$ the race to offer cost-effective, comprehensive health care for all, many entrants are galloping along at breakneck speed. They all want to spend their time at the races well and leave with a little more money in their pockets than they had, when they arrived. But acquiring vast wealth at the races is almost impossible, and reaping immediate financial reward by addressing public health issues is similarly unlikely. At the track, selecting the three entrants who will cross the finish line in their exact order (betting a trifecta) has a low probability of winning, but the payoffs can be large. In the same way, selecting a strategy that ensures that public health, managed care, and pharmacy all cross the finish line together may be long on odds, but packed with payoff in terms of improved public health

In this country, data guides strategic planning for public health. The first of the three documents reviewed here is the list of ten great public health achievements between 1900 and 1999 compiled by the Centers for Disease Control (see Table 1, page 14).' Full-length articles on each achievement were published as a series in the Morbidity and Mortality Weekly Reports in 1999. This list demonstrates that public health improvements have significantly increased both the quantity and quality of life for Americans, and have changed the way medicine is practiced
When reviewing the history of public health over the past century, managed care providers can see certain trends emerging. These trends include better prevention, improved drug interventions, and increased emphasis on personal responsibility for good health.

As we enter the 21 st century, two additional documents that describe our public health initiatives, well can be used to plot the course on our race to better health. These are the report of the Institute of Medicine (IOM) on medication errors, To Err Is Human: Building a Safer Health System, and Healthy People 2010, from the U.S. Department of Health and Human Services (DHHS). ${ }^{2,3}$

\section{IOM Report On Errors} and Healthy People 2010

The IOM's 1999 report, To Err Is Human: Building a Safer Health System, suggests that as many as 98,000 people die each year from medical errors. The number of deaths cited may be controversial, but the report heightened public awareness of this problem. ${ }^{4}$ The implications to pharmacy practice are serious; the public now. perceives this error rate to be a societal menace that needs attention.

Healthy People 2010 is the latest in a series of health initiatives by the DHHS, building on the 1979 Surgeon General's report, Healthy People, and on Healthy People 2000: National Health Promotion and Disease Prevention Objectives. Healthy People 2010 is the current health-promotion and disease-prevention initiative that aims to improve the health of all Americans, eliminate disparities in health, and improve years and quality of healthy life.

Healthy People 2010, as the prevention agenda for the United States, has several parts. It includes 28 focus areas with a total of 467 specific objectives (see Table 2, page 15). Leading indicators have been developed to ensure periodic data-based measurement of progress. Opportunities for managed care to improve health care delivery and disease prevention clearly exist in all of the focus areas, but for managed care pharmacy, focus area 17 , medical product safety, is the most important.

Healthy People 2010 and the IOM report have a common goal: safety. Medical products - including drugs, biologicals, and medical devices-provide great public benefit. Although medical products approved by the Food and Drug Administration (FDA) must be safe, this does not mean that they are without risk. Safe products have reasonable risks, given the magnitude of expected benefit compared with other alternatives.

Use of a medical product involves a choice that must be made after probable benefit is compared with possible risk. Efforts to manage risk at the community, national, and global levels represent the most difficult challenge facing public 
TABLE 1 Ten Great Public Health Achievements, United States, 1900-1999

\begin{tabular}{|c|c|}
\hline Achievement Area & Outcome Examples \\
\hline Vaccinations & $\begin{array}{l}\text { Eradication of smallpox and polio; control of } \\
\text { measles, rubella, tetanus, diphtheria, and others. }\end{array}$ \\
\hline Motor vehicle safety & $\begin{array}{l}\text { Increased seat belt and helmet use; decreased drunk } \\
\text { driving. }\end{array}$ \\
\hline Safer workplaces & $\begin{array}{l}\text { Decreased incidence of silicosis and black-lung } \\
\text { disease; better workplace safety. }\end{array}$ \\
\hline Infectious diseases & $\begin{array}{l}\text { Improved water sanitation, decreasing cholera and } \\
\text { typhoid; effective antibiotics for tuberculosis and } \\
\text { sexually transmitted diseases. }\end{array}$ \\
\hline Heart disease and stroke & $\begin{array}{l}\text { Better treatment of hypertension, leading to decline } \\
\text { in death rates; risk-factor identification and } \\
\text { modification. }\end{array}$ \\
\hline Safer, healthier food & $\begin{array}{l}\text { Decrease in foodborne disease (typhoid, tuberculosis, } \\
\text { botulism); improved prevention of chronic disease } \\
\text { via improved nutrition. }\end{array}$ \\
\hline Healthier mothers and babies & Decreased maternal and infant mortality. \\
\hline Family planning & Availability of safe, effective birth-control methods. \\
\hline Fluoridation of drinking water & Decreased dental caries. \\
\hline Tobacco use & Recognition of all types of tobacco as health hazards. \\
\hline
\end{tabular}

Source: Ten Great Public Health Achievements-United States, 1900-1999. MMWR 1999; 48 (12): 241-48, or www. cdc.gov/phtm/tenachievements/mmwr/mmwr.htm.

health officials. Communities and stakeholders should be actively involved in the decision-making process to determine an acceptable level of risk. This is called risk confrontation. ${ }^{5}$ This process recognizes that community and social values are as important as technical judgments. Simply put, science provides statistical assessment, and society decides the acceptability of risk. Although some advocacy communities are willing to accept a high degree of risk (e.g., AIDS and cancer patients), others, such as those who oppose mandatory vaccination, believe that no risk is acceptable.

Focus area 17 of Healthy People 2010 has five specific objectives that pertain to pharmacy:

- 17.1: monitoring of adverse medical events,

- 17.2: linked, automated information systems,

- 17.3: provider review of medication taken by patients,

- 17.4: receipt of useful information from pharmacies, and

- 17.5: receipt of oral counseling from prescribers and dispensers.

These objectives are developed extensively in Healthy People 2010, including identification of potential data sources and steps needed to ensure improved performance.

\section{1: Monitoring of Adverse Medical Events}

The United States has an elaborate system to balance risks and benefits. The system promotes development, testing, manufacturing, labeling, prescribing, and dispensing in ways that maximize benefit and reduce risk. Most managed care pharmacists are familiar with the FDA's premarketing review and approval process, as well as its postmarketing surveillance programs. As more products are approved for marketing, postmarketing surveillance to identify risk factors becomes increasingly important.

These surveillance systems rely on manufacturers, the health care delivery system, individual providers, and patients for data. Regrettably, the comprehensive system lacks the integration needed to ensure optimal public health and safety. Experts estimate that millions of adverse events associated with medical products occur each year, some resulting in death. ${ }^{6}$

Sources of unintended outcomes from adverse events fall into four categories: (1) product defects, (2) known side effects, (3) medication or device errors, and (4) remaining uncertainties. Table 3, page 16, gives examples of each type of medical product risk.

Many factors contribute to increased risk. The growing complexity of medical technology, economic pressures, and frequent organizational changes in health care institutions increase the potential for unanticipated or unintended outcomes. Consequently, postmarketing surveillance must change from a passive system to one that is proactive in its strategy. The new strategy must examine organizations' use of medical devices, the way problems are perceived and reported, and the range of factors that contribute to any adverse event. The FDA, in an effort to improve the system, is making significant outreach efforts to stakeholders to solicit their ideas, opinions, and concerns.

\section{2: Linked, Automated Information Systems}

Data-collection systems that would allow analysis of disparities in adverse events among different population groups do not exist. Socioeconomic and age-related physiological stress factors predispose 


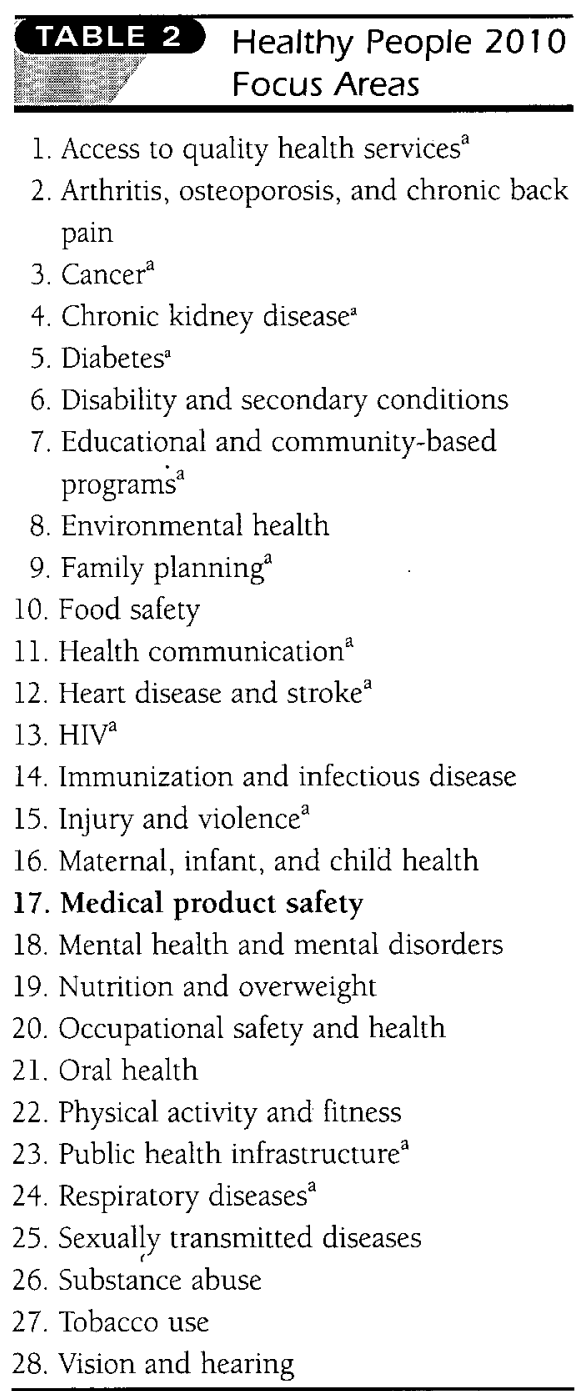

${ }^{a}$ Objectives that relate directly to

Focus Area 17.

certain groups to poor health outcomes. People age 65 and older, for example, take the greatest number of prescription medications. ${ }^{7}$ One-third of the elderly people who are discharged from the hospital taking three or more prescription medications for chronic conditions are rehospitalized within six months; $20 \%$ of these readmissions are related to drug problems. ${ }^{8}$ Among the elderly, 28\% of hospitalizations are attributable to noncompliance with drug therapy and adverse events. ${ }^{9}$ Ample evidence exists that the elderly as a group are at increased risk.

The health care industry is recognizing the demand for a technology-driven infrastructure to capture patient-specific data. Elaborate software programs could allow groups and individuals to benefit from information sharing. Although available, this technology is used only minimally today in select health care settings. In its most evolved state, the technology automates a patient's entire medical record. This electronic medical record often employs artificial intelligence that checks for appropriate indications, incompatibilities, or dosing ranges. It also provides historical information rapidly.

There are barriers to the use of advanced information technology systems. Patient confidentiality is a leading concern. Policymakers are attempting to address this issue through legislative and regulatory proposals designed to protect patients from inappropriate disclosure of their medical history. Once this issue is resolved, the circumstances under which medical information can be shared will be clear, and outcomes for individual patients and groups should improve.

\section{3: Provider Review of Medication Taken by Patients}

The goal of this objective is to increase the proportion of primary care providers, pharmacists, and other health professionals who incorporate routine review of prescription and over-the-counter (OTC) medications into their discussions with patients. Patients who are over age 65 or who have chronic illnesses or disabilities are targeted. There is a tendency for these patients to have multiple illnesses, see multiple physicians, visit multiple pharmacists, and consume a disproportionate share of medications. All of these patterns increase the likelihood of $\cdot$ an adverse event or drug interaction. In 1998, an American Medical Associations' House of Delegates Report urged physicians to make medication review with patients a routine office practice. The report also urged physicians to include compliance, benefit, and adverse effects in their discussions with patients.

Medication reviews are critically impor- tant in long-term therapy, as patients in these target groups take more prescribed and OTC drugs than other groups and have additive therapies for their conditions.

\section{4: Receipt of Useful Information from Pharmacies}

This objective suggests that information provided to patients often lacks useful content, or is formatted in a way that impedes understanding. Congress enacted legislation in 1996 calling on the private sector to develop a means of providing useful written information with every prescription by 2006. The DHHS approved the "Action Plan for the Provision of Useful Prescription Medicine Information" in January 1997. According to this plan, patient information materials were to be evaluated by the Food and Drug Administration (FDA) or DHHS in 1999 and again in 2000.

The Healthy People 2010 objective on linked computer systems has been met. In 1995, 98\% of pharmacies were using computers. Data for providers who review medications for older patients and for the proportion of patients who receive written and verbal information for new prescriptions is showing progress. However, the proportion of adverse drug reports sent to the FDA voluntarily and regarded as serious has declined slightly, moving away from the target.

Additionally, since March of 1999, federal regulations have required OTC manufacturers to provide information in a specific format. ${ }^{10}$ The intent is to improve readability and comprehension for the majority of consumers, thus increasing both safety and efficacy. The initiative emphasizes wording in plain English, a designated order of information, use of larger type, and a series of formatting and graphic design guidelines. ${ }^{11}$ Most important to pharmacists, the phrase "Ask your doctor," has been amended to read "Ask your doctor or pharmacist."

\section{5: Receipt of Oral Counseling from Prescribers and Dispensers}

Opportunities for oral counseling arise in the prescriber's office and at the pharmacy. 
TABLE 3 Types of Medical Product Risks

\begin{tabular}{l|l}
\hline Product defects & For pharmaceuticals, includes lack of potency or lack of purity. \\
\hline Known side effects & $\begin{array}{l}\text { Usually identified in the product's package insert; the source of } \\
\text { the majority of injuries or deaths related to its use. }\end{array}$ \\
\hline $\begin{array}{l}\text { Medication or } \\
\text { device errors }\end{array}$ & $\begin{array}{l}\text { The incorrect use of a prescribed product, or the } \\
\text { incorrect operation or placement of a medical device. }\end{array}$ \\
\hline Remaining uncertainties & $\begin{array}{l}\text { A degree of uncertainty always exists about benefits and risks; } \\
\text { these include unexpected side effects, long-term effects, and } \\
\text { effects in populations not studied before marketing. }\end{array}$ \\
\hline
\end{tabular}

In both settings, written information is greatly enhanced if oral counseling supplements it. In a 1997 national symposium on oral counseling, medical professionals indicated that counseling levels are low because patients do not understand the need to know about their medications, patients do not demand or expect counseling, and patients and payors do not understand the value of counseling. ${ }^{12}$

This means that patients and payors must be educated about the value of oral counseling. Toward this end, the American Pharmaceutical Association (APhA) established a policy in 1997 stating that pharmacists should provide drug-related information to their patients in face-toface oral consultation, and supplement it with written materials or other tools suited to the individual patient's needs, such as help numbers or Web sites.

Individual needs may include simpler information. Low literacy increases vulnerability and poor health outcomes, and low-literacy patients are rarely empowered. ${ }^{13}$ They do not understand written directions, and are apt to receive lowerquality care. Literacy problems are concentrated in populations that are likely to use public programs, so different educational approaches may be needed to teach health care information. A variety of educational formats in several reading levels must be available to help this effort.

\section{Implications for}

\section{Managed Care Pharmacists}

The gates are open, and the contestants are running. Most managed care pharma- cists will need to change their approach and execution of duties to meet the public health challenges identified by the IOM's report and Healthy People 2010.

To meet objective 17.1, existing (i.e., automated and manual adverse drug reaction screening) systems will have to be strengthened and formalized. Addressing the remaining objectives in focus area 17 will help patients make informed decisions, and may reduce adverse events.

Objective 17.2 calls for greater electronic prescribing and claims processing edits. This will improve our safety margin, and prompt or educate health care providers. Objective 17.3 promotes constant review of medication profiles, and face-to-face interaction with patients to ensure that OTC drugs or alternative therapies are considered. Managed care pharmacists should anticipate the need for useful information as described in objective 17.4, and include a requirement for well-designed and written patient information in network participation agreements. Consideration of the directives that now apply to OTC labeling--use of plain English and larger typewill help us to better meet patient needs. Finally, objective 17.5 suggests that managed care pharmacists must overcome any obstacle to effective counseling by implementing APhA's policy.

\section{Conclusion}

Will public health, managed care, and pharmacy comprise a trifecta in 2010 ? Can we learn from the achievements of the past century to continue to make progress in the next? What must we do to ensure that we all cross the finish line at the same time?

Every managed care organization and pharmacist must understand this decade's public health issues. Managed care pharmacists who become more aware of public health issues can help their organizations find solutions to new challenges. If health care providers use Healthy People 2010 and the IOM's report on medication errors as visitors to a race track use the daily racing forms and program, we may achieve a perfect trifecta: Public health, managed care, and the pharmacy profession can all win.

\section{References}

1. Ten great public health achievements-United States, 1900-1999. MMWR 1999; 48(12): 24148.

2. Kohn LT, Corrigan JM, Donaldson M, eds. To err is human: building a safer health system. Washington: Institute of Medicine, 1999

3. Healthy People 2010. www.health.gov/healthypeople/PrevAgenda/focus.htm.

4. McDonald CJ, Weiner M, Hui SL. Deaths due to medical errors are exaggerated in Institute of Medicine report. JAMA 2000; 284(1): 93

5. Leviton LC; Needlemen CE, Shapiro MA. Confronting public health risks: a decision maker's guide. Thousand Oaks, CA: Sage Publications, 1998.

6. Lazarou JH, Pomeranz B, Corey PN. Incidence of adverse drug reactions in hospitalized patients. JAMA 1998; 279(15): 1200-05

7. U.S. General Accounting Office. Prescription drugs and the elderly. AO/HEHS-95-152 Washinglon: GAO, 1995

8. Bero LA, Lipton HL, Bird JA. Characterization of geriatric drug-related hospital readmissions. Medical Care $1991 ; 29(10): 989-1003$

9. Col N, Fanale JE, Kronholm P. The role of medication noncompliance and adverse drug reactions in hospitalization of the elderly. Arch of Int Med 1990 ; 150(4): $841-45$.

10. Over the counter labeling for drug manufacturers. Federal Register 1999; 64(51): 13253-303

11. Pharmacists hail OTC labeling inclusion. Drug Utilization Review 1999; 1.5(6): 95.

12. Morris LA, Tabak ER, Gondek K. Counseling patients about prescribed medication: 12-year trends. Medical Care 1997; 35(10): 996-1007

13. Ad hoc committee on health literacy for the council on scientific affairs. JAMA 1999; 281(6): 552-57. 